\title{
Spindle Cell Lipoma: A Rare, Misunderstood Entity
}

\author{
Bommie Florence Seo, \\ In Sook Kang, \\ Deuk Young Oh \\ Department of Plastic and Reconstructive \\ Surgery, College of Medicine, The Catholic \\ University of Korea, Seoul, Korea
}

No potential conflict of interest relevant to this article was reported.

\begin{abstract}
Spindle cell lipoma, a rare variant of lipoma, is a benign tumor found in the posterior neck and shoulder. A 24-year-old man with a close family history of malignant lymphoma had presented with a large, firm, nodular mass found in the right supraclavicular area. Excision of the deeply located mass revealed a pale yellow, rubbery nodule which grossly resembled an enlarged lymph node, with a variant of lymphoma as a primary suspect. However, pathological studies revealed the lesion to be a spindle cell lipoma. Although atypical in location, spindle cell lipoma should always be kept in differential diagnosis of a newly-noted soft tissue mass, as this entity may be easily cured by simple excision.
\end{abstract}

Keywords: Atypical lipoma / Head and neck tumor / Rare diseases

\section{INTRODUCTION}

Spindle cell lipoma is an uncommon variant of lipoma, characterized by mature adipocytes and small uniform spindle cells. The lesion usually presents in male patients between the age of 40 to 60 , and is located in the subcutaneous layer of the posterior trunk, shoulder and posterior neck [1]. This entity should be differentiated from a number of benign and malignant tumors, including soft tissue sarcomas such as liposarcoma.

\section{CASE REPORT}

A 24-year-old, otherwise healthy, male patient presented with a palpable mass in the right supraclavicular area. He had first noticed the mass 3 years prior to visit, and had grown slowly during this period. Review of symptoms was negative for B-symptoms such as fever, weight loss, and night sweats. Family history was significant for his mother, who was receiving treatment for malig-

Correspondence: Deuk Young Oh

Department of Plastic and Reconstructive Surgery, Seoul St. Mary's Hospital, College of Medicine, The Catholic University of Korea, 222 Banpodaero, Seocho-gu, Seoul 137-701, Korea

E-mail: ohdeuk1234@hanmail.net

Received June 27, 2014 / Revised July 28, 2014 / Accepted August 3, 2014 nant lymphoma.

Physical examination revealed a firm, nontender mass around $3 \mathrm{~cm}$ in diameter in the right supraclavicular area. The mass did not compromise movement in the neck or the shoulder. Computed topography identified the subcutaneous mass to be $3.4 \mathrm{~cm} \times 1.9$ $\mathrm{cm}$ in size, round, well circumscribed, of mixed fat density (Fig. 1).

Excision and biopsy was performed under local anesthesia. The mass was pale yellow, oval shaped. It was deep within the subcutaneous tissue, abutting an underlying muscle. A thin layer of fibrous tissue had encircled the mass, all of which was excised from the surrounding adipose layer. Gross examination revealed an oval encapsulated mass measuring $3 \times 2 \mathrm{~cm}$, that resembled an enlarged lymph node (Fig. 2). In the context of family history, a tumor of lymphatic origin was the anticipated. However, histopathological examination was reported as mature adipocytes admixed with ropey collagen bundles and scattered spindle cells arranged in parallel fascicles, a diagnosis of spindle cell lipoma (Fig. 3).

The wound healed without problems, and no recurrence had been noted during the 6-month follow-up period.

\section{DISCUSSION}

Spindle cell lipoma, a distinct histological variant of lipoma, origi- 
nates from adipose tissue, and is characterized by the replacement of mature fat by collagen-forming spindle cells. The lesion was originally described by Enzinger and Harvey [2] in 1975, and accounts for about $1.5 \%$ of all lipomas [1]. It is most commonly found in males between the ages of 40 to 60 with a peak in the sixth decade. Syed et al. [3] suggested this male predilection was attributable to the frequent detection of androgen receptors in this tumor.

This entity is most commonly found in the subcutaneous layer of the posterior neck, shoulder or upper back. However, it has been reported to occur in the anterior neck, suprasellar region, buccal fat pad, esophagus, nasal vestibule, tongue, floor of mouth, vallecula, parotid gland, hypopharynx, larynx, breast, and medi- astinum [4]. Growth is slow, and the average diameter of the tumor reported as 4 to 5 centimeters. The tumor is usually solitary and painless. Rare cases of multiple lesions including familial cases have been reported [5].

The exact pathogenesis is yet to be established. The origin of the spindle cells have been proposed as fibroblasts, adipocytes, immature mesenchymal cells, and CD34-positive dendritic interstitial cells $[1,6]$. Histologically, the lesion consists of mature adipocytes and small uniform spindle cells mixed with eosinophilic collagen bundles within a myxoidstroma. This is unlike lipoma, which typically only has an adipocyte component forming a lobular pattern embedded in a collagenous matrix. The spindle cells

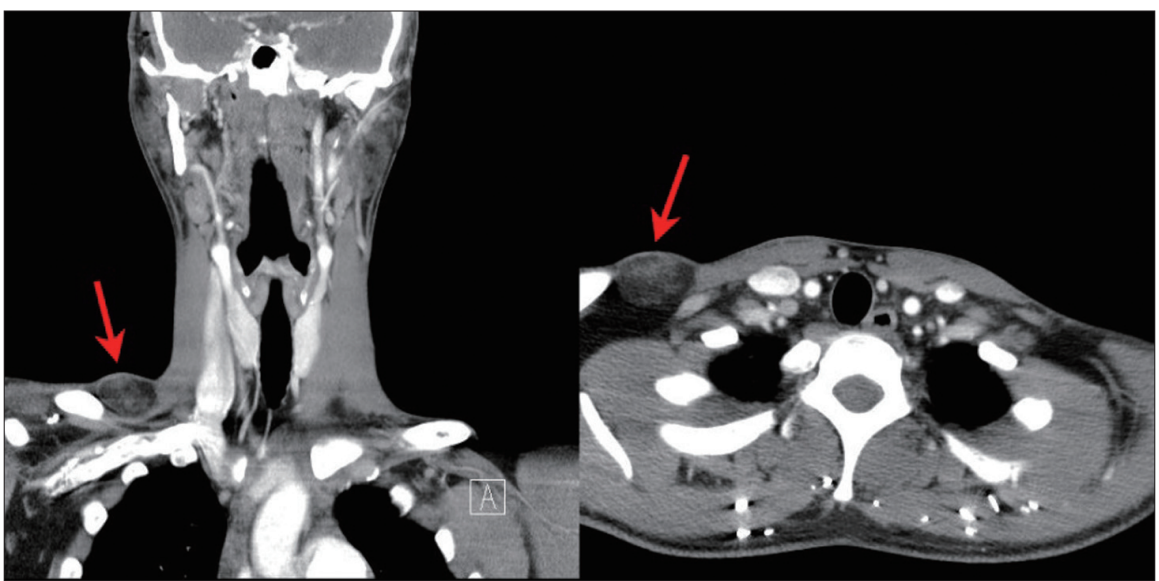

Fig. 1. Preoperative computed tomography images. A $3.4 \times 1.9 \mathrm{~cm}$, round, well circumscribed mass with heterogenous density (red arrows) is seen in the subcutaneous layer of the right supraclavicular region.

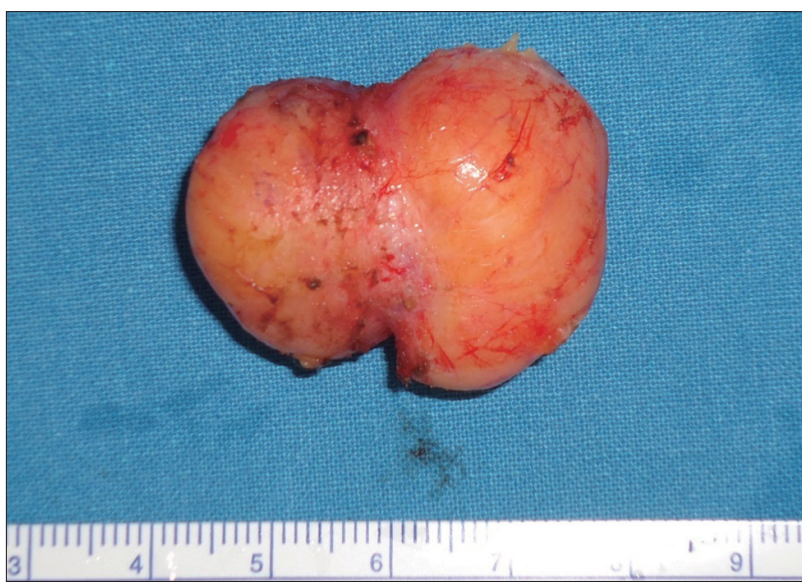

Fig. 2. The $3 \times 2 \mathrm{~cm}$ sized, ovoid nodule that was excised. Unlike typical lipomas, the mass was quite firm and rubbery in texture.

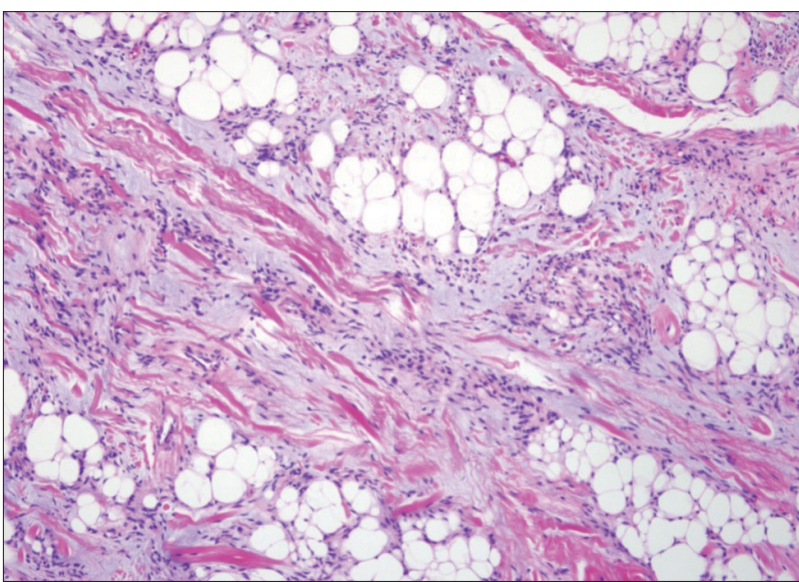

Fig. 3. Histological image of the specimen revealing mature adipocytes interspersed between wavy collagen bundles and spindle cells $(\mathrm{H} \& \mathrm{E}, \times 100)$ 
are positive for CD34 but negative for S-100 protein on immunohistochemistry stains. However, CD34 is not specific for spindle cell lipomas, and other tumors along the spectrum of differential diagnosis of lipomas may also stain positive for this marker. Spindle cell lipomas are desmin negative and express losses of chromosomes $12 \mathrm{q}$ and/or 16q, which may help the diagnosis [7].

Differential diagnoses include a spectrum of benign lipomatous tumors consisting of mature fat cells with or without other mesenchymal tissue elements. The World Health Organization categorizes these into the following: lipoma, lipomatosis, lipomatosis of nerve, lipoblastoma, angiolipoma, myolipoma, chondroidlipoma, spindle cell/pleomorphic lipoma, and hibernoma. Spindle cell lipoma has been reported to be found inside of an intramuscular lipoma and coexisting lipomas with spindle cell lipomas [8]. Other entities to differentiate include neurofibroma, nuchal fibroma, cellular angiofibroma, extramammarymyofibroblastoma, dermatofibrosarcoma, and schwannoma. However, the most important differential diagnosis is well-differentiated liposarcoma. Well-differentiated liposarcoma is usually found in the extremities or retroperitoneum of older patients, with equal gender distribution, and with less well-defined borders. Careful histological observation will reveal infiltrative features, cellular pleomorphism, rich vascularization, and pronounced mucoid matrix. Frequent recurrence of an excised 'lipoma' may also indicate liposarcoma. Unlike spindle cell lipoma, for which local excision is sufficient, liposarcoma requires extensive wide excision.

Diagnosis is difficult to make based on radiological images, owing to the wide spectrum of imaging features produced by the variation in the ratio between fat and spindle cells, with fat free or low-fat spindle cell lipomasat one extreme. In the case presented, computed topography revealed the mass to have a confluence of fat and fibrous densities. While the patient's young age and absence of B-symptoms suggested lipoma, the intraoperative examination of rubbery lymphatic tissue, the location of mass reaching deep into the supraclavicular area, along with family history of lymphoma, a diagnosis involving lymphatic tissue was expected. Fortunately, pathological examination revealed the lesion to be a spindle cell lipoma, an entity treatable by simple excision.

While spindle cell lipoma is well known between pathologists and dermatologists, it is a relatively unfamiliar clinical entity to most surgeons, who rely on patient history, physical examinations, and radiological imaging for diagnosis. However, radiological information may cause difficulty in differentiating between the various soft tissue tumors. Gross examination of the mass itself is equally unspecific, also rooting from the diverse ratio between fat and spindle cells. Although atypical in location, spindle cell lipoma should always be kept in mind when approaching a newly noted, soft tissue mass, as this entity may be easily cured by simple excision.

\section{REFERENCES}

1. Fletcher CD, Martin-Bates E. Spindle cell lipoma: a clinicopathological study with some original observations. Histopathology 1987;11: 803-17.

2. Enzinger FM, Harvey DA. Spindle cell lipoma. Cancer 1975;36:1852-9.

3. Syed S, Martin AM, Haupt H, Podolski V, Brooks JJ. Frequent detection of androgen receptors in spindle cell lipomas: an explanation for this lesion's male predominance? Arch Pathol Lab Med 2008;132:81-3.

4. D'Antonio A, Mottola G, Caleo A, Addesso M, Boscaino A. Spindle cell lipoma of the larynx. Ear Nose Throat J 2013;92:E9.

5. Fanburg-Smith JC, Devaney KO, Miettinen M, Weiss SW. Multiple spindle cell lipomas: a report of 7 familial and 11 nonfamilial cases. Am J Surg Pathol 1998;22:40-8.

6. Suster S, Fisher C. Immunoreactivity for the human hematopoietic progenitor cell antigen (CD34) in lipomatous tumors. Am J Surg Pathol 1997;21:195-200.

7. Miettinen MM, Mandahl N. Spindle cell lipoma/pleomorphic lipoma. In: Fletcher CD, Unni KK, Mertens F; World Health Organization; International Agency for Research on Cancer, editors. Pathology and genetics of tumours of soft tissue and bone. Lyon: IARC Press; 2002. p.31-2.

8. Laliotis A, De Bree E, Vasilaki S, Papadakis M, Melissas J. Co-existence of intramuscular spindle cell lipoma with an intramuscular ordinary lipoma:report of a case. Pol J Pathol 2013;64:224-7. 